DOI: http://dx.doi.org/10.11606/issn.1984-4867.v25i2p337-353

\title{
Estratégias Empreendedoras em Associações de Condutores dos Parques Nacionais Piauienses: propostas de educação ambiental e responsabilidade socioambiental.
}

\section{Entrepreneurial Strategies in Tourist Guides Associations of National Parks in the State of Piaui: proposals for environmental education and environmental responsibility.}

\section{Estrategias Empresariales en Asociaciones de Conductores de Turismo de Parques Nacionales del Estado de Piaui: propuestas para la educación ambiental y responsabilidad ambiental}

\author{
Paulo Jordão Fortes ${ }^{1}$ \\ Gaia Rego Fortes ${ }^{2}$
}

\section{Resumo}

Este artigo é o resultado do projeto de extensão da Universidade Federal do Piauí (UFPI), PROEXT 2009/edital 06. As estratégias sugeridasforam apresentadas no seminário de capacitação desenvolvido para os condutores de visitantes do Parque Nacional Serra da Capivara (PNSC) e Parque Nacional Sete Cidades(PN7C). Foram traçados dois objetivos principais. O primeiro foi criar formas inovadoras para gerar soluções em unidades de conservações a partir do conhecimento previamente adquirido pelos condutores de visitantes. $\mathrm{O}$ segundo objetivo era identificar comoestes condutores poderiam criar novas formas de explorar a atividade turística ao mesmotempo em que benefícios sociais, econômicos e ambientais pudessem ser alcançados com estas medidas empreendedoras. Para medir as forças e fraquezas internas do ambiente de trabalho dos condutores, foi utilizada a metodologia de Manzato (2005, 2007), previamente validada na classificação do turismo arqueológico. Após o agrupamento da opinião dos condutores sobre o ambiente interno, foram ofertadas oficinas para elencar as principais oportunidades e ameaças do ambiente externo. Esta etapa proporcionou o levantamento de todas as variáveis necessárias para uma análise SWOT a partir do conhecimento e da perspectiva dos condutores dos referidos parques.

Palavras-chave: Unidades de Conservação, SWOT, educação ambiental

\footnotetext{
${ }^{1}$ Mestre em Gestão Empresarial pela Fundação Getúlio Vargas (FGV). Graduado em Business Administration pela University of Nebraska at Omaha (UNO). Professor de Administração de Empresas da Universidade Federal do Piauí (UFPI). Brasil. E-mail: paulojordao@ufpi.edu.br.

${ }^{2}$ Mestre em Desenvolvimento e Meio Ambiente pela UFPI. Bacharel em Comunicação Social pelo Centro de Ensino Unificado de Teresina. Brasil. E-mail: gaiarego@ hotmail.com.
} 


\begin{abstract}
This article is the result an extension project at UFPI, named PROEXT 2009/edital 06. It suggested strategies were presented during the training seminar developed for visitor's guides to the National Park Serra da Capivara (PNSC) and Seven Cities National Park (PN7C). The project had two main objectives. The first was to create innovative ways to generate solutions in conservations units from the previously acquired knowledge by the local guides. The second objective was to identify how these guides could create new ways to explore the tourist activity and, at the same time, that social, economic and environmental impacts could be achieved with these entrepreneurial activities. To measure the internal strengths and weaknesses of the guides work environment, we used the methodology Manzato (2005, 2007), previously validated in the classification of archaeological tourism. After grouping the guides views regarding the internal environment, were offered workshops to outline the main opportunities and threats in the external environment. This seminar provided a survey of all the variables needed for a SWOT analysis from the knowledge and perspective of the drivers of these parks.
\end{abstract}

Keywords: Conservation units, SWOT, environmental education.

\title{
Resumen
}

Este artículo es el resultado de un proyecto de extensión en UFPI, llamado PROEXT 2009/edital 06. Sugirió estrategias fueron presentadas durante el seminario de capacitación elaborado para las guías de los visitantes al Parque Nacional Serra da Capivara (PNSC) y Siete Ciudades Parque Nacional (PN7C). El proyecto tenía dos objetivos principales. El primero fue la creación de formas innovadoras de generar soluciones en unidades de conservación a partir de los conocimientos previamente adquiridos por los guías locales. El segundo objetivo fue identificar cómo estas guías podrían crear nuevas maneras de explorar la actividad turística y, al mismo tiempo, que los impactos sociales, económicos y ambientales se podrían lograr con estas actividades empresariales. Para medir las fortalezas y debilidades del entorno de guías de trabajo internos, se utilizó la metodología Manzato (2005, 2007), previamente validado en la clasificación del turismo arqueológico. Después de agrupar los puntos de vista guías sobre medio ambiente interno, se ofrecieron talleres para delinear las principales oportunidades y amenazas en el entorno externo. Este seminario proporcionó un estudio de todas las variables necesarias para un análisis SWOT de los conocimientos y la perspectiva de los conductores de estos parques.

Palabras clave: las unidades de conservación, análisis SWOT, la educación ambiental. 


\section{Introdução}

\subsection{A profissão dos condutores dos PN7C e PNSC}

O constante fluxo de visitantes ${ }^{3}$ e turistas ${ }^{4}$ em unidades de conservação proporcionou a discussão sobre os impactos dos turistas dentro de parques nacionais. As unidades de conservações possuem a finalidade de aliar o turismoà conservação do meio ambiente (BRASIL, 2006). Por outro lado, a The Ecoturism Society alerta que a crescente demanda por serviços de ecoturismo pode trazer danos irreparáveis a estas unidades (SILVA, PINTOS \&GOMES, 2008).

A atividade turística tem se tornado uma das maiores forças para a criação de áreas de proteção ambiental, seja por promover uma atividade econômica, como o ecoturismo, como por proteger as unidades de impactos negativos (PUPPIM DE OLIVEIRA, 2005, 2008). O turismo no interior e em volta de áreas protegidas pode ajudar a manter o equilíbrio entre a preservação ambiental, que é a maior razão para as unidades de conservação existirem e, fomentar outras atividades criadas pela atividade turística, como por exemplo, restaurantes, hospedagem e pequenos empreendimentos de serviços.

Os PNSC e PN7C exercem a prática do ecoturismo e de arqueoturismo. Danos ao meio ambiente nestas unidades podem significar a depredação dos biomas presentes em ambos os parques, assim como possíveis danos ao patrimônio pré-histórico presentenos parques: pinturas rupestres, monumentos naturais, fósseis de animais pré-históricos, vestígios de populações indígenas, além de outros achados arqueológicos que podem vir a ser catalogados.

Os danos ao patrimônio não deveriam acontecer nesses ambientes, segundo alguns autores, pois o ecoturismo é visto como um turismo responsável, no qual o visitante sabe a extensão de suas ações ao meio ambiente (SILVA, PINTO \& GOMES, 2008). O ecoturismo é definido como uma

\footnotetext{
${ }^{3}$ Visitante é a pessoa que visita a área de uma Unidade de Conservação de acordocom os propósitos e objetivos de cada área, possuindo várias motivações: lazer, conhecimento, recreação, contemplação, entre outras (BRASIL, 2006).

${ }^{4} \mathrm{O}$ turista é um indivíduo que se desloca para um local diferente de sua residência habitual, motivado por diversos interesses. Durante a sua permanência no local, o turista, utiliza-se de alguns serviços como hospedagem, alimentação, transporte e contratação de guias (BRASIL, 2006).
} 
"viagem responsável a áreas naturais, visando preservar o meio ambiente e promover o bem estar da população local" (WESTERN, 1999, p.17). O turismo arqueológico se encaixa na mesma categoria de ecoturismo e este é predominante nos parques analisados. O arqueoturismo consiste em:

Processo decorrente do deslocamento e da permanência dos visitantes a locais denominados sítios arqueológicos, onde são encontrados vestígios remanescentes de antigas sociedades, sejam elas pré-históricas, e ou históricas, passíveis de visitação terrestre ou aquática (MANZATO, 2005, p. 44).

Estas modalidades de turismo possibilitam o uso racional de recursos turísticos por populações urbanas e podem ser responsáveis pela transformação de práticas sociais de apropriação da natureza, possibilitando assim uma melhor possibilidade de educação ambiental (BEDIM, 2009).

Em ambas as categorias, turismo ecológico e arqueológico, se faz necessária apresença do guia, condutor e/ou monitor. A denominação dada à profissão é realizada de acordo com o plano de manejo de cada unidade de conservação, através de leis estaduais, e da necessidade local de se criar uma profissão que gere renda local através do turismo.

No PNSC a capacitação dos condutores de turismo se dá através de cursos ministrados pela associação local, a Associação dos Condutores de Visitantes Ecoturísticos do Parque Nacional da Serra da Capivara, em parceria com a Fundação Museu do Homem Americano (FUMDHAM). No PN7C a capacitação dos condutores se dá através de cursos da associação local, Associação de Condutores de Visitantes em Ecoturismo do Meio Norte do Piauí, em parceria com o Instituto Chico Mendes de Conservação da Biodiversidade (ICMBio).

A atividade turística, segundo o IBAMA (2006), aomesmo tempoem que fortalece a apropriação das unidades de conservações pela sociedade, incrementa a economia e promove a geração de emprego e renda para as populações locais. As unidades são geralmente utilizadas como fonte de instrumentalização da educação ambiental (SERRANO, 2000). 
Dentro desta perspectiva de conservação do meio ambiente e exploração de uma atividade turística encontram-se os condutores dos PN7C e PNSC. Segundo relato dos profissionais envolvidos nos arranjos turísticos, a atividade de condutor é geralmente menosprezada pela população local e por turistas, que não concordam em pagar pela utilização dos profissionais. Até mesmo por pesquisadores, que entendem que os condutores não são necessários para acompanhálos nos parques.

Oliveira Filho (2007) descreve um fato que retrata a constante preocupação na conservação de um parque. Em estudo realizado no PNSC, o pesquisador detectou que 49,89\% dos visitantes estavam dispostos a dar uma contribuição extra para a conservação do parque. Dos $50,11 \%$ visitantes que não estavam dispostos a pagar a mesma contribuição, 67\% o faziam por acreditarem ser de reponsabilidade do governo a conservação dos parques, e não da sociedade. Grande parte dos entrevistados, $95,75 \%$, considerou importante a conservação dessas áreas, mas transfere o ônus da ação para o governo. Os dados retratam que os nossos ecoturistas ainda não são totalmente conscientes das ações de depredação e apropriação do patrimônio de áreas integralmente protegidas.

A vivência diária dos condutores de ambos os parques está inserida ao questionamento: de quem é o papel de proteger uma área de proteção ambiental? O Estado, na figura de suas instituições.Asociedade civil. Independente da resposta, na prática, o condutor é o agente que protege as unidades de conservação da própria sociedade, que a depreda de forma direta ou indireta. Assim, o condutor protege o turista dele mesmo e de suas ações antrópicas ao patrimônio. A profissão do condutor, seja ela exercida em parques nacionais, geoparques e parques arqueológicos, é imprescindível devido à reduzida conscientização ambiental dos visitantes.

O uso de condutores não é exclusivodo estado do Piauí, outras unidades possuem tais condutores e monitores com responsabilidades e obrigações relacionadas a atividades que compreendem: acompanhamento dos visitantes, orientação e transmissão de informações sobre determinado atrativo natural; contribuindo também para a redução dos impactos negativos que os ecoturistas possam causar no ambiente (TORRES, 2008). 
Os condutores de unidades de conservações cumprem função vital na cadeia produtiva do turismo, sendo agentes incumbidos de prestar informações sobre os atrativos do meio natural, informações históricas, incentivar atitudes conservacionistas entre os turistas e cuidar da segurança dos grupos, além de servirem como agentes de denúncia do meio ambiente (BARBOSA \& ZAMBONI, 2000). Com o aparecimento do termo e do conceito de desenvolvimento sustentável precisamente no relatório de Brundtland (1987), intitulado Nosso Futuro Comum, houve a necessidade de se discutir a sustentabilidade em sua interface com fatores sociais, econômicos e ambientais. Diante desta referência, a preservação ambiental deve ser aliada da justiça social.

Os parques nacionais são unidades de conservação de uso indireto,ou seja, são áreas destinadas a proteção integral, embora permitam o desenvolvimento de serviços de amenidades no seu interior, como o arqueoturismo e o ecoturismo; ainda que enfatize a mínima interferência na natureza, esse tipo de unidade não desconsidera que o homem também compõe o meio ambiente. É necessário investimento direto na formação de condutores de forma a realçar a necessidade de desenvolver capacidades que garantam a esta profissão ser um meio de educação ambiental. Outro fator a ser destacado é que essa ação pode ser uma estratégia para que a relação entre condutores e turistas promova momentos de aprendizagem.

\section{Desenvolvimento}

\subsection{Análise SWOT}

Porter (1979, 2008), Hall \&Saias (1980),exemplificam que forças externas e forças competitivas moldam as estratégias das empresas. Porter(2008) define cinco forças que são determinantes nas estratégias de sobrevivência das empresas:

1) Ameaças de Novos Entrantes;

2) Poder de Barganha dos Clientes;

3) Poder de Barganha dos Fornecedores; 
4) Ameaças de Produtos Substitutos;

5) Rivalidade entre os Concorrentes.

Nos casos analisados, as forças externasse fazem presentes principalmente nos quesitos ameaça de novos entrantes (1), poder de barganha dos clientes (2) epoder de barganha dos fornecedores (3). A ameaça aos produtos substitutos e a rivalidade entre os concorrentes não se fazem presentes, pois somente existe uma associação de condutores em cada parque, portanto, não há forças competitivas atuando.

A força de ameaça de novos entrantes é retratada pela entrada de novos agentes, como novos condutores.No PNSC, por exemplo, já existem biólogos, arqueólogos e outros profissionais que estão se formando como guias de turismo pelo Instituto Federal do Piauí(IFPI) e que já são condutores no parque. Alguns destes novos agentes já fazem parte da associação localantes de estarem formados como guias de turismo.

Outro viés dessa força de ameaçarelatada é o alto nível de capacitação dos novos profissionais dos parques, que em geral são profissionais do turismo e empreendedores que migram para regiões que possuem oportunidades turísticas. Geralmente são profissionais pré-qualificados, ou que possuem maior poder de investimento. A inserção de um novo membro mais capacitado tem dupla consequência:pode estimularos outros membros a se profissionalizarem, mesmo que motivados por competição, ou pode servir de estímulo para abandonarem suas atividades de condutores de visitantes.

O poder de barganha dos fornecedores e dos clientes não propicia aos condutores uma forma facilitada para o gerenciamento de seus negócios ao barganharem com seus clientes, no caso os turistas.Como os condutores possuem poucas atividades organizadas e pouco capital disponível, as alternativaspara conseguirem novas atividades são limitadas.

Ilustra este dilema algumas iniciativas, como a venda de camisetas com o emblema da unidade de conservação por parte doscondutores do PNSC. Os condutores conseguem comprar as camisas para vender, mas o lucro desta atividade fica em parte na mão dos produtores das camisas, que dão desconto apenas emgrandes contratos. O turista, com sua mente dirigida à prática de 
barganha, se beneficia também ao conseguir algum desconto, mas reduz o lucro do condutornessas atividades.

O ambiente externo nas teorias de administração posteriores ao estruturalismo é parte determinante no desenvolvimento de estratégias (CHIAVENATO, 2004). As constantes modificações de mercado, as incertezas humanas, as novas tendências e tecnologias, obrigam empresas a mudarem seus ambientes internos ao ponto de atenderem as demandas externas; tal característica se dá pelo simples motivo do mercado ser a fonte de sustento das empresas. Entende-se também que uma empresa, sozinha, é incapaz de mudar o mercado, assim faz-se necessário o ajuste interno.

Whittington (2002) salienta que no mercado atual desenvolveu-se o conceito de empresa evolucionária. Esta seria uma empresa que visa maximizar os lucros e que possui estratégias emergentes, ou seja, uma empresa que contém estrutura interna flexível a ponto de conseguir reagir a modificações do mercado e incrementar os lucros.A estratégia SWOT serve paraidentificar como as organizações, no caso as unidades de conservações piauienses, poderiam aprimorar-se para melhor servir a sociedade e conservar o patrimônio natural.

Fica claro então que para qualquer empreendimento moderno é necessário uma atenção especial para as forças de mercado. Pequenos empreendimentos não podem mudar seus ambientes externos sozinhos.

A metodologia SWOT foi escolhida pela simplicidade de sua utilização para a criação de estratégias, principalmente as de longo prazo.Mesmo que empresas e organizações tenham que resolver problemas imediatos, asestratégias são utilizadas para guiar as empresas nas possíveis tendênciasde como o mercado deve se desenvolver nos próximos anos. Decisões estratégicas devem possuir um foco de pelo menos uma década; também devem ser baseadas nas necessidades dos clientes e acessibilidade dos mesmos, ou para diversificar as atividades de uma empresa,ou de seus produtos e serviços (PORTER, 1996).

No caso das unidades de conservação que são regidas por conselhos a estratégia de utilizar o condutor como um facilitador para aplicação de melhoriaspodem acelerar o tempo de 
implementação das mesmas.Os condutores são agentes ativos na conservação e manutenção destes espaços de proteção integrale,mesmo não sendo remunerados diretamente pelas organizações que coordenam os parques, estes agentes são sustentados pela atividade turística dos parques nacionais presentes no território piauiense.

Após a análise SWOT identificou-se que ambas as associações não possuíam estratégias a serem traçadas apesar do valor que esta atividade tem para a proteção do meio ambiente e para geração de renda e de justiça social. Essa percepçãodemonstrou a necessidade de criação da missão inicial das associações de condutores de forma a possibilitar melhor direcionamento à profissão. Não se pode deixar de perceber a importância do condutor como educador ambiental e agente de conservação do meio ambiente. Diante do exposto, estipula-se a missão inicial a ser adequada pelas associações: "Propiciar ao turista segurança e entretenimento na visitação ao parque, a manutenção do patrimônio e servir como agente de educação ambiental".

Durante as seções, ficou evidente que os turistas reconhecem a importância do condutor, principalmente como agente de educação ambiental. Mesmo assim os condutores são reconhecidos,por alguns pares de ambos os arranjos turísticos em que estão inseridos,como pessoas que recebem dinheiro para vigiar o turista e não para expandir sua consciência ecológica de alguma forma.

Na realidade os condutores são verdadeiros guardiões dos parques. Estes protegem o patrimônio para o turista e do próprio turista. Desta forma, o condutor trabalha conscientizando o visitante de que suas ações repercutem sobre o patrimônio natural, legitimando-se como um agente de educação ambiental. Por este motivo, o serviço de educação ambiental foi dimensionado na missão de ambas as organizações.

As estratégias criadas foram quase que exclusivamente oriundas das fraquezas internas dos parques, pois a resolução de problemas ou fraquezas internas pode dar aoscondutores uma nova atividadegeradora de renda, enquanto este profissional realiza sua função social.Para cada combinação de força ou fraqueza (fatores ambientais internos) com oportunidades e ou ameaças 
(fatores ambientais externos) são originadas quatro tipos de estratégiaspossíveis (WEIHRICH, 1982):

1) Combinação de Oportunidades e Forças (Maxi-Maxi = Estratégia agressiva, considerada como de ataque, confronto ou de desenvolvimento de mercado);

2) Combinação de Oportunidades e Fraquezas (Mini-Maxi = Estratégia defensiva para proteção de suas fragilidades internas ou de crescimento de mercado);

3) Combinação de Ameaças e Forças $($ Maxi-Mini = Estratégias de reforço para reduzir ameaças ou de manutenção de mercado);

4) Combinação de Ameaças e Fraquezas (Mini-Mini = Estratégia de desistência, de retirada ou de sobrevivência).

Como as estratégias foram predominantemente focadas em fraquezas internas, estas são classificadas como de crescimento (estratégias oriundas de fraquezas e oportunidades) sobrevivência (estratégias oriundas de fraquezas e ameaças).

\subsection{Materiais e métodos}

O presente projeto utilizou a metodologia de Manzato $(2005,2007)$ para elencar as variáveis que compõem o serviço de turismo arqueológico. As 17 variáveis foram consideradas como instrumento para aferir forças e fraquezas em um ambiente interno concebido por uma análise SWOT. Adaptou-se o formulário de Manzato para utilizar,sobretudo,a perspectiva dos condutores em relação a cada variável que compõe o serviço de turismo arqueológico do PNSC e PN7C. Os setenta e dois (72) condutores opinaram em relação a cada variável como: Muito Adequado (MA), Adequado (ADQ), Indiferente (IND), Pouco Adequado (PA), Inadequado (INAD) e Inexistente (INEX).

Uma vez compostaa base de dados,o resultado quantitativo de cada variável foi compreendido pelo pesquisador como uma força ou uma fraqueza do parque. As forças foram determinadas pelo somatório de todas as respostas de cada variável classificada como: Muito Adequado ou Adequado. As fraquezas são determinadas pelo somatório de todas as repostas de cada variável 
classificada como: Pouco Adequado, Inadequado e Inexistente. As respostas Indiferentesforam retiradas da análise.

Após a classificação sistemática de cada variável e análise dos dados, o resultado foi divulgado e discutido em cada associação de condutores. Nesta sessão foram elencadas estratégias e projetos a serem desenvolvidos pelas associações para incremento de renda dos condutores e para despertar a percepção por parte dos grupos de sua função social dentro de parques nacionais. Cada projeto, seja ele de responsabilidade das associações ou da UFPI/CAFS, foi classificado como de curto prazo (melhorias as serem realizadas em até 3 meses), em médio prazo (melhorias a serem realizadas entre 3 meses e 1 ano) e como longo prazo (melhorias a serem realizadas em um período superior a 1 ano).

O estudo salienta que as variáveis que receberam valores similares entre forças e fraquezas, ou seja, com valores próximos a 50\%, foram retirados das tabelas de análise SWOT.Mas, para que estas variáveis não ficassem sem a devida atenção durante a reunião de validação, as associações tiveram a oportunidade de discutir sobre essas questões, caso houvesse a necessidade de criação de uma estratégia específica para esses eventos.

\subsection{Resultados}

As estratégias geradas por este projeto foram desenvolvidas em conjunto entre os membros das associações de condutores e os colaboradores da UFPI. Para que as associações internalizassem as estratégias,a equipe da UFPI,somente interferiu com suas opiniões sobre as melhorias quando o grupo se demonstrou favorável à realização das mesmas.

Foram propostas sete estratégias a serem traçadas pelas associações. Três destas estratégias serão prioritárias para o desenvolvimento de ambos os grupos, por poderem ser implementadas nos dois parques.A UFPI poderá contribuir para ambas as instituições de forma isonômica. A seguir, na tabela 1 ,enumeram-seas seguintes estratégias:as metas a serem traçadas, os elementos internos e externos que fomentaram a criação das estratégias, a classificação do tipo de estratégia, o prazo para sua execução e os parques nos quais as melhorias serão implantadas. 
Tabela 1 - Classificação de estratégias a serem implantadas

\begin{tabular}{|c|c|c|c|c|c|c|}
\hline Estratégias & $\begin{array}{l}\text { Ambiente } \\
\text { Interno }\end{array}$ & $\begin{array}{l}\text { Ambiente } \\
\text { Externo }\end{array}$ & $\begin{array}{c}\text { Tipo de } \\
\text { Estratégia }\end{array}$ & $\begin{array}{c}\text { Instituição } \\
\text { Responsável }\end{array}$ & Prazo & $\begin{array}{c}\text { Local de } \\
\text { Implantação }\end{array}$ \\
\hline $\begin{array}{l}\text { Estratégia } 1 \text { - } \\
\text { Criação de página } \\
\text { na internet }\end{array}$ & $\begin{array}{l}\text { Força - } \\
\text { Utilização de } \\
\text { parceria coma } \\
\text { UFPI }\end{array}$ & $\begin{array}{l}\text { Oportunidade } \\
\text { - Inexistência } \\
\text { de serviço }\end{array}$ & Crescimento & UFPI & $\mathrm{MP}^{*}$ & $\begin{array}{l}\text { PNSC e } \\
\text { PN7C }\end{array}$ \\
\hline $\begin{array}{l}\text { Estratégia } 2- \\
\text { Criação de mapas } \\
\text { por artistas locais }\end{array}$ & $\begin{array}{l}\text { Fraqueza - } \\
\text { Material de } \\
\text { divulgação } \\
\text { dosparques }\end{array}$ & $\begin{array}{l}\text { Oportunidade } \\
\text { - Inexistência } \\
\text { de produto. }\end{array}$ & Sobrevivência & $\begin{array}{l}\text { Associações de } \\
\text { Condutores }\end{array}$ & $\mathrm{CP} *$ & $\begin{array}{l}\text { PNSC e } \\
\text { PN7C }\end{array}$ \\
\hline $\begin{array}{l}\text { Estratégia } 3 \text { - } \\
\text { Criação de } \\
\text { aplicativo que } \\
\text { permita turistas } \\
\text { estrangeiros a } \\
\text { possuir } \\
\text { informações dos } \\
\text { parques }\end{array}$ & $\begin{array}{l}\text { Fraqueza - } \\
\text { Inexistência } \\
\text { de condutores } \\
\text { bilíngues }\end{array}$ & $\begin{array}{l}\text { Oportunidade } \\
\text { - Inexistência } \\
\text { de produto } \\
\text { e/ou serviço }\end{array}$ & Sobrevivência & UFPI & LP* & $\begin{array}{l}\text { PNSC e } \\
\text { PN7C }\end{array}$ \\
\hline $\begin{array}{l}\text { Estratégia } 4- \\
\text { Criação de } \\
\text { cooperativa de } \\
\text { transporte }\end{array}$ & $\begin{array}{l}\text { Fraqueza - } \\
\text { Inexistência } \\
\text { de transporte } \\
\text { coletivos para } \\
\text { os parques } \\
\end{array}$ & $\begin{array}{l}\text { Oportunidade } \\
\text { - Inexistência } \\
\text { de serviço }\end{array}$ & Sobrevivência & $\begin{array}{l}\text { Associação de } \\
\text { condutores do } \\
\text { PNSC }\end{array}$ & LP* & PNSC \\
\hline $\begin{array}{l}\text { Estratégia } 5 \text { - } \\
\text { Inserção de novos } \\
\text { pontos de água no } \\
\text { parque }\end{array}$ & $\begin{array}{l}\text { Fraqueza - } \\
\text { Vasta } \\
\text { extensão do } \\
\text { PNSC, e } \\
\text { pouca oferta } \\
\text { de pontos de } \\
\text { venda }\end{array}$ & $\begin{array}{l}\text { Oportunidade } \\
\text { - Reduzir } \\
\text { peso } \\
\text { carregado e } \\
\text { aumentar } \\
\text { conforto do } \\
\text { turista }\end{array}$ & Sobrevivência & $\begin{array}{l}\text { Associação dos } \\
\text { Condutores do } \\
\text { PNSC }\end{array}$ & $\mathrm{CP} *$ & PNSC \\
\hline $\begin{array}{l}\text { Estratégia 6- } \\
\text { Análise de } \\
\text { viabilidade de } \\
\text { implantação de } \\
\text { apicultura e } \\
\text { meliponicultura no } \\
\text { entorno do parque }\end{array}$ & $\begin{array}{l}\text { Fraqueza- } \\
\text { Condutores do } \\
\text { PN7C são } \\
\text { obrigados a } \\
\text { ficar no } \\
\text { parque e } \\
\text { esperar por } \\
\text { turistas }\end{array}$ & $\begin{array}{l}\text { Oportunidade } \\
- \\
\text { Desenvolver } \\
\text { nova } \\
\text { atividade que } \\
\text { conserve o } \\
\text { meio } \\
\text { ambiente e } \\
\text { utilize tempo } \\
\text { ocioso }\end{array}$ & Sobrevivência & UFPI & LP* & PN7C \\
\hline $\begin{array}{l}\text { Estratégia } 7- \\
\text { Utilização do lixo } \\
\text { reciclável do } \\
\text { PN7C como } \\
\text { incremento de } \\
\text { renda }\end{array}$ & $\begin{array}{l}\text { Força - } \\
\text { Parceria } \\
\text { constante com } \\
\text { o ICMBio em } \\
\text { ações para } \\
\text { incremento de } \\
\text { renda }\end{array}$ & $\begin{array}{l}\text { Oportunidade } \\
\text { - Melhores } \\
\text { práticas de } \\
\text { manejo do } \\
\text { lixono parque } \\
\text { e educação } \\
\text { ambiental }\end{array}$ & Crescimento & $\begin{array}{l}\text { Associação dos } \\
\text { Condutores do } \\
\text { PN7C }\end{array}$ & ASD* & PN7C \\
\hline
\end{tabular}




\section{Conclusão}

A profissão de condutores nos PNSC e PN7C, segundo relato dos próprios profissionais, é depreciada por vários membros da cadeia produtiva do serviço de turismo. Segundo os condutores, os turistas demonstram maior simpatia pela profissão se comparados aos outros agentes dos arranjos. Esta relação conflituosa entre os pares que compõem os arranjos turísticos originados de unidades de conservação pode ser ilustrada pelo fatodos condutores necessitarem de ajuda de outras instituições para que a profissão continue sendo dignificada.

Diante do exposto,estas associações ainda não dispõem de estrutura organizada suficiente para a manutenção e auto reconhecimento do valor intrínseco como guardiões dos parques nacionais do Piauí e como agentes de reestruturação da relação homem-natureza.

A ausência de uma missão orientadora, em ambas as associações, demonstra que mesmo que estas existam para propiciar melhorias na profissão, os condutores não se identificam com o propósito das associações. Isto aliado adificuldades estruturais, como ausência deacesso a internet e telefone nas instalações das associações, disponibilidadede páginas de internet com informação para turistas, entre outras dificuldades, impedem o desenvolvimento de demaisatividades geradoras de renda. Dentre as associações, somente a do PN7Cpossui sede na qual os condutores poderiamusar tais meios de relacionamento com turistas diariamente.

No PN7C, o ICMBio proporcionou uma parceira junto à associação contemplandoa mesmacom estrutura física e facilidade para a alimentação de seus associados. O instituto também demonstra preocupação com outras atividades geradoras de renda ao permitir que a associação comercialize alguns itens de necessidade básica para o turista. Porém,distância de 22 kmdasede com a cidade mais próxima, Piripiri, impede a seus associados de possuírem uma linha de telefonia fixa na sede, além de conexão com a internet e comunicação via telefones celulares. É de vital importância que o fator tecnologia seja incorporado em todos os parques nacionais do Piauí; a disponibilidade de serviços oferecidos por provedoras de celulares (linhas de telefone e internet) facilitam os momentos de aprendizagem na dinâmicada profissão do condutor no passeio com os turistas. 
Atualmente uma imagem ou vídeo disponibilizado via internet com um PDA ou smartphonepoderia ser uma estratégia eficiente de divulgação do turismo piauiense; as redes sociais podem ser utilizadas como fonte de fomento ao turismo. Entende-se neste estudo que o ICMBio possui papel vital na dignificação da profissão dos condutores no PN7C, vide que trabalha como uma instituição de apoio local à atividade turística e na implantação de inovações que contribuem positivamente para geração de renda local.

No PNSC, os condutores possuem parceria com umaescola local de ensino fundamental que cede uma de suas salas de aula para a associação realizar suas assembleias. Esta associação também não possui telefone fixo e acesso a internet. Os condutores podem ser achados via telefone celular devido à maioria residir em São Raimundo Nonato, ou porpossuírem um bom relacionamento com a rede hoteleira.

Em ambos os parques fica evidente que deficiências estruturais das localidades no entorno dos parques, como por exemplo, a ausência de serviços de telefonia móvel, fixo e internet, dificulta a inserção de serviços empreendedores que necessitam de tecnologia. Tambéma deficiência estrutural de ausência de transporte público capaz de tornar facilitado o acesso aos parques, dificulta ainda mais o desenvolvimento de atividades de suporte ao turismo e de auxílio à população local que trabalha em ambos os parques.

A profissão do condutor será dignificada, principalmente pela própria classe, ao se iniciar ainternalizaçãode uma missão que compreenda o real significado da profissão de condutor. O condutor há de vender seu serviço de condução, garantindo que o turista entre e saia seguro do parque, recebendo todas as informações necessárias para um passeio turístico. Este profissional o fará percebendo que sua função de guardião do parque compreende entender que o conhecimento sobre o patrimônio natural estimula o processo de educação ambiental. Dessa forma o valor do serviço de condução pago pelo turista será justificado, pois se trata de um momento de troca e de ambientalização desse meio em que condutores e turistas fazem parte.

Também deve ser relatado que as próprias associações devem criar suas precificações de serviço sem qualquer interferência externa de outras organizações. As práticas de estabelecimento de 
precificação por outras instituições podem restringir o funcionamento das associações, pois as organizações de apoio local envolvidas nos arranjos turísticos analisados não possuem em suas missões a orientação para controle mercadológico. O mercado deve ser o melhor balizador para este preço, ou seja, um valor justo para o turista e digno para o condutor.

Dentre as sete estratégias traçadas, cinco estratégias, ou seja, 71,4 \% são de sobrevivência. Em relação às estratégias traçadas por ambas as associações, houve predominância de defensivas, ou Mini-Maxi. Este cenário foi desenvolvido pelo fato do projeto estar focado nos pontos fracos do ambiente interno.

É imperativo que, em um projeto de extensão, o grupo executor preze por desenvolver ações de ajuda à sociedade; assim foi a compreensão da equipe ao dispor de melhorias realizáveis para suprir fraquezas observadas nos parques analisados. Este posicionamento vislumbra queestas melhorias, em primeiro lugar,aprimorem o relacionamento entre as associações e organizaçõesde apoio aos parques, legitimando propostos de desenvolvimento local compartilhado. Desta forma, ao inserir novas atividades geradoras de renda nas associações que são componentes dos arranjos turísticos, espera-se que as estratégias sejam percebidas de uma forma positiva. Com o desenvolvimento destas ações nas associações, almejamos enfatizar sua condição de pertencimento a áreas de proteção integral e, portanto, pretendemos mudar a visão de outros membros da cadeia produtiva em relação a profissão de condutores de turistas.

Este projeto de extensão dará origem a outros projetos de extensão e pesquisa entre as associações. Diante do exposto, a UFPI continuará a contribuir significativamente para a concepção de novas atividades empreendedoras que ajudem a desenvolver o potencial turístico da região sul do Piauí, como também atuar no desenvolvimento de capacidades que resultem em um meio ambiente equilibrado em todas as suas dimensões.

\section{Referências}

BARBOSA, M. A. C; ZAMBONI, R. A. Formação de um "cluster" em torno do turismo de natureza sustentável em Bonito-MS. Brasília, 2000. 49p. Disponível em: 〈http://www.ipea.gov.br/pub/td/td_2000/td_772.pdf>. Acesso em: 16 set. 2011. 
BEDIM, B.P., CAMPOS, C.F.; VIDAL, T.C. Equipamentos turísticos do parque estadual do Itacolomi (MG): análise das instalações e dos atrativos construídos. Revista Brasileira de Ecoturismo, São Paulo, v.3, n.2, p.283-314, 2010.

BRASIL. Diretrizes para visitação em Unidades de Conservação. Áreas Protegidas do Brasil. Documento Elaborado pela Secretaria de Biodiversidade e Florestas, MMA, Brasília, 2006.

CHIAVEnATO, I. Teoria Geral da Administração. 7 ed. São Paulo: Campus, 2004, 650 p.

DOUROJEANNI, M. J; PÁDUA, M. T. J. Biodiversidade: a hora decisiva. Curitiba: EUFPR/FBPN, 2001. 307p.

HALL, D. J; SAIAS M. A. Strategy Follows Structure. Strategic Management Journal, v.1. p. 149-163, 1980.

MANZATO, F. Turismo Arqueológico: diagnóstico e análise do produto arqueoturístico. Revista de Turismo y Patrimônio Cultural, v. 5, n.1, p. 99-109, 2007. Disponível em: 〈http://www.passoonline.org >. Acesso em: 23 out. 2011.

. Turismo Arqueológico: diagnóstico em sítios pré-históricos no Estado de São Paulo. Caxias do Sul, 2005. X p. Dissertação (Mestrado em Turismo). Universidade de Caxias do Sul.

NOSSO FUTURO COMUM (Relatório Brundtland). Comissão Mundial sobre o Meio Ambiente e Desenvolvimento. Rio de Janeiro: Editora da Fundação Getúlio Vargas, 1988.

OLIVEIRA FILHO, R. C. Valoração Econômica da Atividade Turística no Parque Nacional da Serra da Capivara. Piauí, 2007. Dissertação (Mestrado em Desenvolvimento e Meio Ambiente). TROPEN/PRODEMA, UFPI.

PORTER, M. E. The five competitive forces that shape strategy. Harvard Business Review, v. 86, n. 1, p. 78-93, 2008.

. What is Strategy? Harvard Business Review, p.61-78, Nov./Dec. 1996.

. How competitive forces shape strategy. Harvard Business Review, v. 57, n. 2, p. 137-145, 1979.

PUPPIM de OLIVEIRA. J.A. Implementation of Environmental Policies in Developing Countries: A Case of Protected Areas and Tourism in Brazil. Albany, NY: State University of New York - SUNY Press. 2008.

. Tourism as a Force for Establishing Protected Areas: The Case of Bahia, Brazil. Journal of Sustainable Tourism. Channel View Publications, v. 13 (1), p. 24-49. 2005.

SILVA, C. E.; PINTO, J. B.; GOMES, L. J. Ecoturismo na floresta nacional do Ibura como potencial fomento de sociedades sustentáveis. Revista Nordestina de Ecoturismo, Aracaju, v.1, n.1, p.6-17, 2008.

SERRANO, C. (Org.). A educação pelas pedras. São Paulo: Chronos, 2000.

TORRES, E. M. G.Percepções de um grupo de guias de monitores ambientais sobre o ambiente que atuam (PARATY - RJ). Revista de Educação Ambiental, Rio de Janeiro,2008.

WESTERN, D. Definindo ecoturismo. In: LINDBERG, K; HAWKINS, D. E. Ecoturismo: um guia para planejamento e gestão. São Paulo: Senac São Paulo, 1999. p.13-22.

WITTINGTON, R. O que é estratégia? São Paulo: Thomson, 2002. 175 p. 
WEIHRICH, H. The TOWS matrix: a tool for situational analysis. Journal of Long Range Planning, v. 15, n. 2, 1982.

Recebido em: 29/05/2013 (1 $1^{\text {a }}$ versão) 19/08/2013 (última versão)

Aprovado em: 03/09/2013 